\title{
Experimental Investigation of Mechanical Behavior of Glass- Fiber Reinforced Polyurethane ResinComposite in three Different ratios
}

\author{
Sureshkumar.P, Karthick.B, Dinakaran.S, R.Rajapradeepan \\ $P G$ Student, Department of Mechanical Engineering, \\ Sri Krishna College of Engineering and Technology, Coimbatore-641008, Tamil Nadu, India.
}

\begin{abstract}
In this experimental study, the glass fiber reinforced polyurethane composite is prepared and the Tensile, Flexural and Impact Strengths are analyzed.Currently the glass fiber is manufactured with other resins such as epoxy, vinylester and polypropylene. These composites are used as sports goods, automobile bodies, etc. Comparing to other resin the price of polyurethane resin is one third only. The glass fiber reinforced polyurethane composite laminates was prepared by hand layup method and it was placed on the matched plate mold for curing. The composites were manufactured at various ratios such as 30:70, 35:65, and 40:60 (Fiber: Resin). The specimen is prepared from composite laminates andthe mechanical properties such as tensile strength, flexural strength and impact strength has been analyzed as per the ASTM standard D3039, D790 and D256 respectively. The results show the best suitable fiber resin ratio with respect to strength.
\end{abstract}

Keywords-Composite laminate, Hand layup method, match plate mould, ASTM standard

\section{INTRODUCTION}

Glass fibers are the most common of all reinforcing fibers for polymeric matrix composites (PMC). The principal advantages of glass fibers are low cost, high tensile strength, high chemical resistance and excellent insulating properties. The two types of glass fibers commonly used in the fiber reinforced plastics industry are E-glass and S-glass. Another type known as C-glass is used in chemical applications requiring greater corrosion resistance to acids than is provided by E-glass. E-glass has the lowest cost of all commercially available reinforcing fibers, which is the reason for its wide used in the FRP industry.

S-glass, originally developed for aircraft components and missile casings, has the highest tensile strength among all fibers in use. However, the compositional difference and the higher manufacturing cost make it more expensive than E-glass. A lower cost version of S-glass called S-2 glass is also available. Although S-2 glass is manufactured with less-stringent non military specifications, its tensile strength and modulus are similar to those S-glasses.

Glass fibers are available in the form of continuous strand roving, chopped strands and woven roving. Woven cloth is wired using twisted continuous strands called yarns. The form of woven roving is suitable for hand layup moulding. The average tensile strength of glass fiber may exceed $3.45 \mathrm{~N} / \mathrm{mm} 2$. The tensile strength of glass fiber may reduce due to surface damage and presence of water.

The major structural applications for fiber reinforced composite are in the field of automobile components and sporting goods. In automobile applications it is classified in to three groups they are body components, chassis components and engine components. Exterior body components such as hood, door panels require high stiffness and dent resistance as well as Class-A surface finish for appearance. The composite material used for these components is E-glass fiber reinforced sheet moulding compound composite. Other body components are roof frames, door frame, bumper beams, engine valve covers, timing chain covers, oil pan etc.,

Unileaf E-glass fiber-reinforced epoxy springs have been used to replace multi leaf steel springs with as much as $80 \%$ weight reduction. Other structural chassis components such as drive shaft and road wheels have been successfully in the laboratory and further research is going onto regularize for common use.

In sporting goods application the glass fibers reinforced epoxy is prepared over wood and aluminium in pole vault poles because of its high strain energy storage capacity.

A good pole must have a reasonably high stiffness and high elastic limit stress so that the strain energy of the bent pole can be recovered to propel the athlete above the horizontal bar.Other glass fiber sporting goods are surf boards, archery bows and arrows. 


\section{SHEET PREPARATION}

The woven glass fiber is cut into $0.27 \times 0.27 \mathrm{~m}$ size pieces. Polyurethane is made by mixing polyol, methylisocynate and ethylene glycol in the ratio of 6:19:4 respectively and stirred well. The mixed chemicals should be used within 20 minutes to avoid solidification.

The quantity of glass fiber and polyurethane resin to be used for the three different ratios 30:70, 35:65 and 40:60 (Glass: Resin) are calculated based on the definition "density of a material is mass per unit volume".

$$
\begin{gathered}
\mathrm{m}=\rho \mathrm{X} \mathrm{V} \text {------- (1) } \\
\text { where, } \\
\mathrm{m}=\text { Mass of the material in Kg } \\
\rho=\text { Density of the material in } \mathrm{Kg} / \mathrm{m}^{3} \\
\text { Density of glass fiber }-2580 \mathrm{Kg} / \mathrm{m}^{3} \\
\text { Density of polyurethane }-1100 \mathrm{Kg} / \mathrm{m}^{3} \\
\mathrm{v}=\text { Volume of material in } \mathrm{m}^{3}
\end{gathered}
$$

The area of die is $0.3 \times 0.3 \times 0.003 \mathrm{~m}$. The mass of the glass fiber and polyurethane that is used in different ratios are calculated by using the above formula. The calculated values are tabulated.

Table 01: Mass of Material Used Based on Fiber Resin Ratio

\begin{tabular}{|c|c|c|c|}
\hline \multirow{2}{*}{ Material } & \multicolumn{3}{|c|}{ Mass in Kg for different ratio } \\
\cline { 2 - 4 } & $\mathbf{3 0 : 7 0}$ & $\mathbf{3 5 : 6 5}$ & $\mathbf{4 0 : 6 0}$ \\
\hline Glass Fiber & 0.21 & 0.24 & 0.28 \\
\hline Polyurethane & 0.21 & 0.19 & 0.18 \\
\hline
\end{tabular}

The paraffin wax is applied on the lower and upper die plate. The acetate sheet is placed on the wax applied surface of die plate and again wax is applied over the acetate sheet. The stripper plate is placed on the lower die in which the guide pin should match with the stripper plate.

Woven glass fiber pieces is placed on the lower die layer by layer, the polyurethane resin is applied between the every layer of woven glass fiber. Finally the upper die is used to close the match plate mould in which guide pin is used to locate it correctly with lower die.

Die set moved into the compression moulding machine for curing under pressure of $1 \times 10^{7} \mathrm{~Pa}$ and $80^{\circ} \mathrm{C}$ temperature for 4 hours. After curing the composite sheet is removed from the mould set.

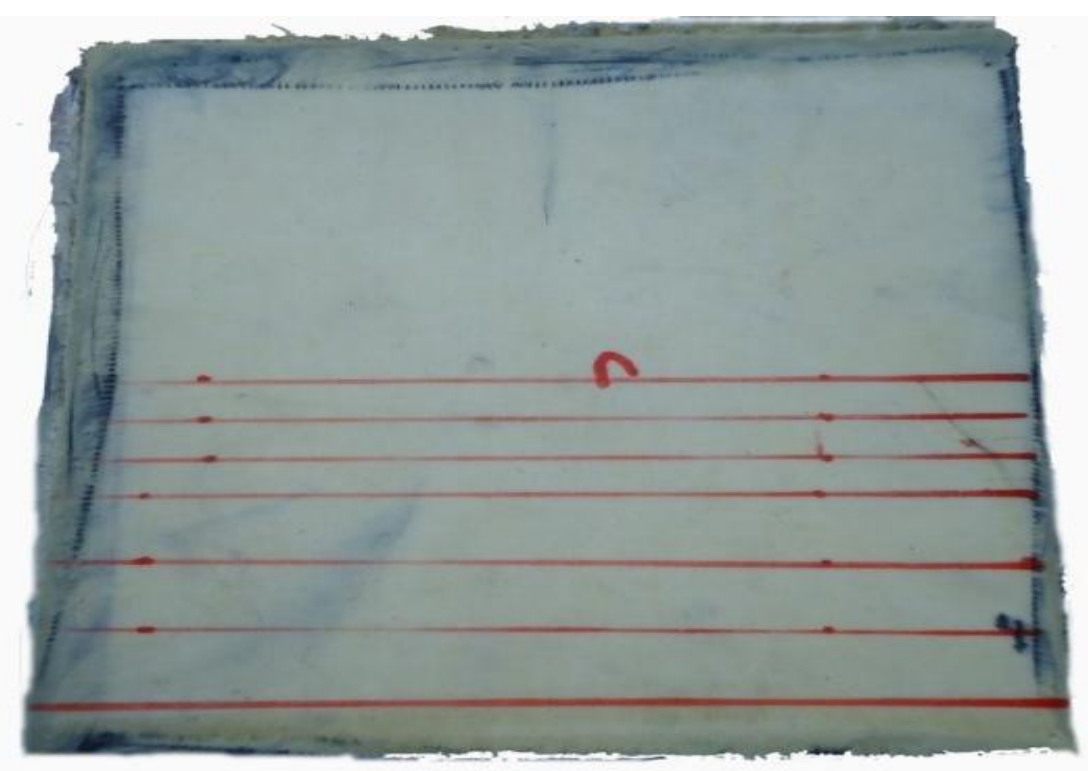

Fig. 01 Glass fiber reinforced polyurethane resin composite sheet 


\subsection{TENSILE STRENGTH TEST}

\section{TESTING}

The specimen is prepared according to the ASTM D3039 standard. The testing is carried out in tensile testing machine with displacement velocity at $1.5 \mathrm{~mm} / \mathrm{min}$. The gauge length for testing specimen is $80 \mathrm{~mm}$. Initially the breadth and width of specimen is observed and the area of cross section is calculated. The output result is a stress strain curve, from this the ultimate stress, elongation percentage, yield stress and break load is calculated. Three specimensare tested for each fiber resin composition ratio.

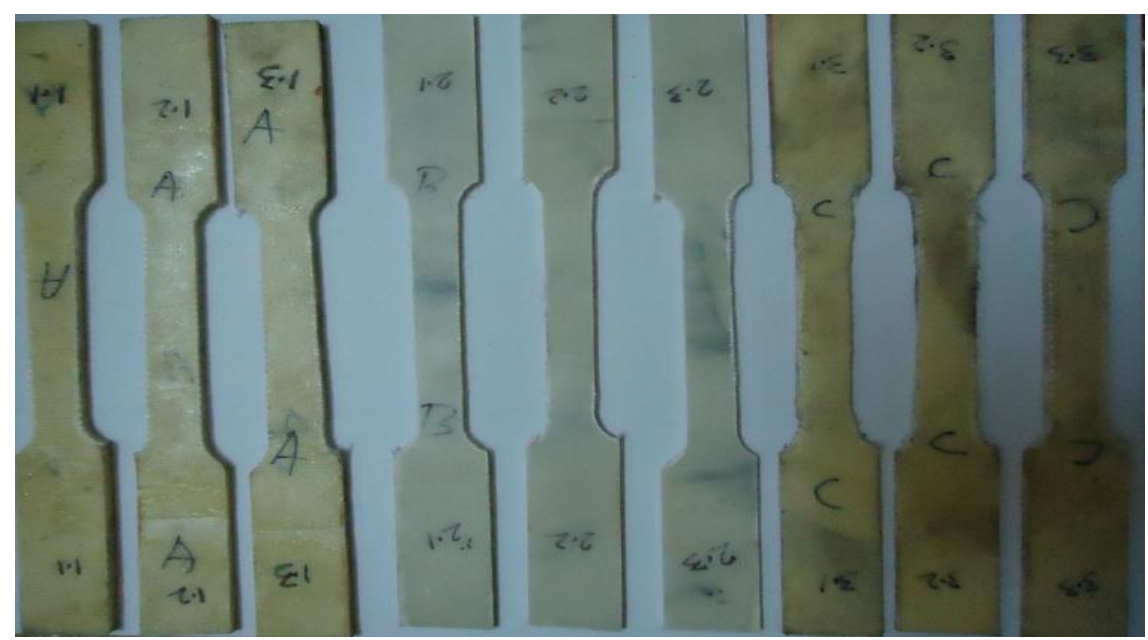

Fig.02 Tensile Strength testing specimens

\subsection{FLEXURAL STRENGTH TEST}

The specimen is prepared according to the ASTM D790 standard. Three point flexural testing method is followed. The testing is carried out in tensile testing machine with displacement velocity at $1.5 \mathrm{~mm} / \mathrm{min}$. The gauge length for testing specimen is $80 \mathrm{~mm}$. Initially the breadth and width of specimen is observed and the area of cross section is calculated. The output result is a load Vs displacement curve, from this result the ultimate stress and break load is calculated. Three specimens are tested for each fiber resin composition ratio.

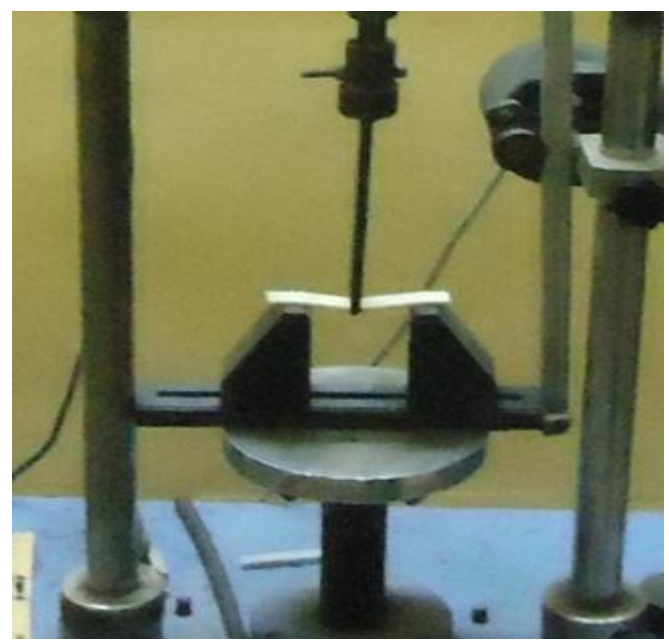

Fig. 03 Flexural testing setup

\subsection{IMPACT STRENGTH TEST}

The specimen is prepared according to the ASTM D256 standard. The testing is carried out in Izod impact testing machine. Initially the breadth and width of specimen is observed and the area of cross section is calculated. The ' $\mathrm{V}$ ' notch in the specimen plays a vital role in testing, so the specimen should be placed in the testing fixture correctly according to the standard.The energy observed by the specimen during testing is directly observed from the pointer scale. Three specimens are tested for each fiber resin composition ratio. 


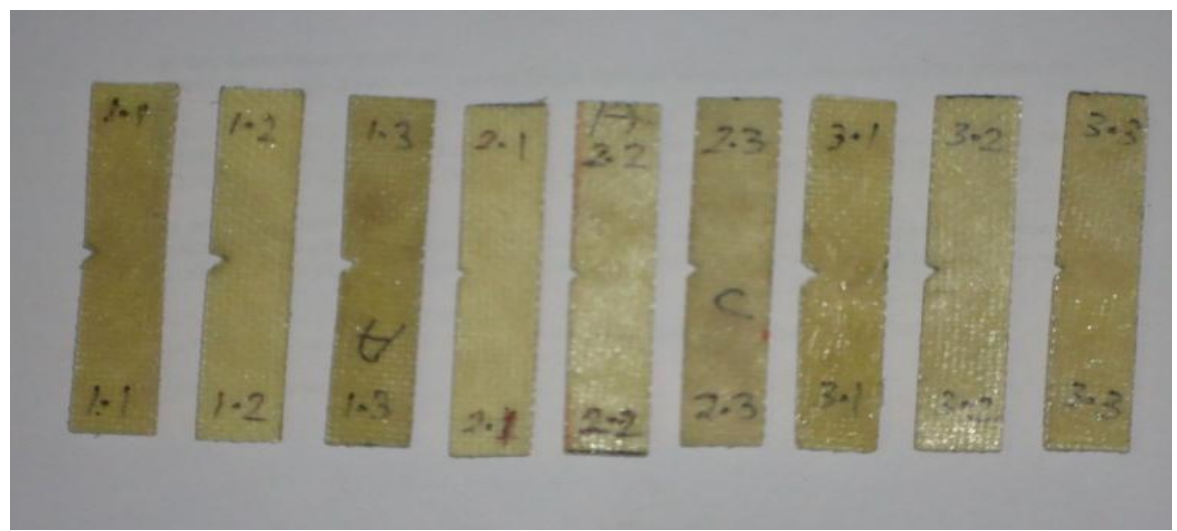

Fig.04Impact Strength Testing specimens

\section{RESULTS AND DISCUSSION}

\subsection{TENSILE STRENGTH}

The results of tensile strength tested components are compiled and the tensile strength is calculated.The fig.05 shows the tensile strength of three different specimens for each ratio. The 40:60 fiber resin ratio has more tensile strength while comparing to other two ratios due to more fiber content. It shows that when fiber content increases the strength of the composite also increases, but at some point it will decline due to lack of bondingelement (Polyurethane). However in this experiment shows the 40:60 fiber resin ratio has high tensile strength while comparing to other two ratios.

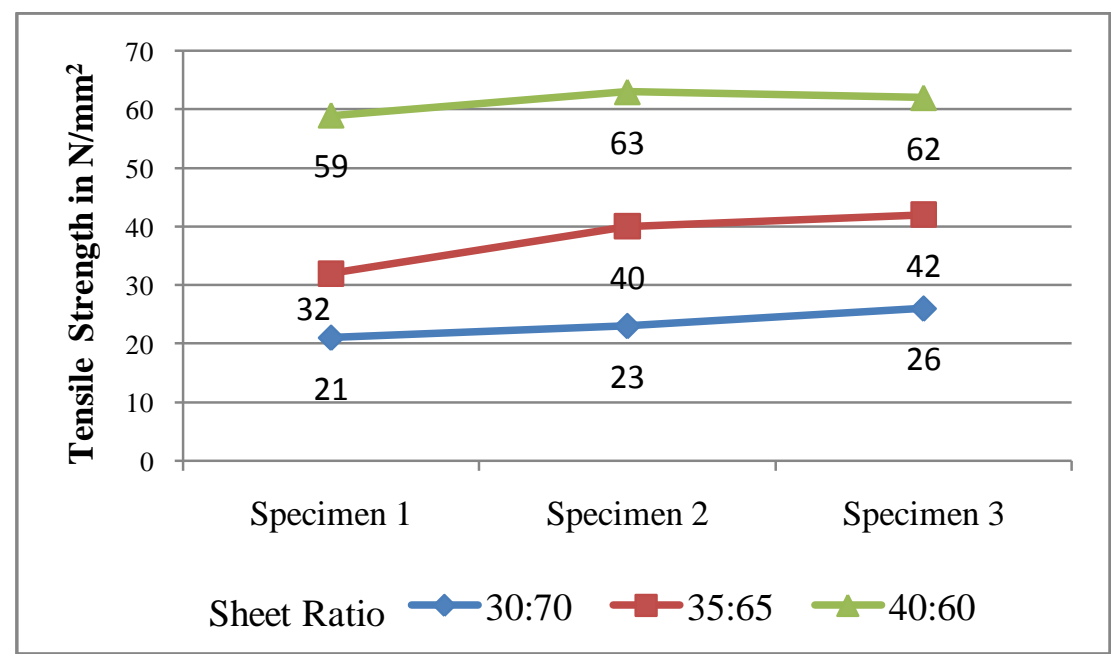

Fig. 05 Tensile strength of glass fiber reinforced polyurethane resin composite vs three different specimen for each ratio

\subsection{FLEXURAL STRENGTH}

From the testing results the flexural strength is calculated by using 3-point flexural formula and the graph is plotted. The fig.06 shows the flexural strength of three specimensfor each ratio. The 40:60 fiber resin ratio has more flexural strength while comparing to other two ratios. The composite has a polyurethane resin which has a very good flexible property, so the material will have high elasticity. Due to this property it can be used for bumpers in cars, mud guard in two wheelers, etc. But at some point the strength will be reduced to lack of bonding element (polyurethane). However this experiment shows the 40:60 fiber resin ratio has high flexural strength while comparing to other two ratios. 


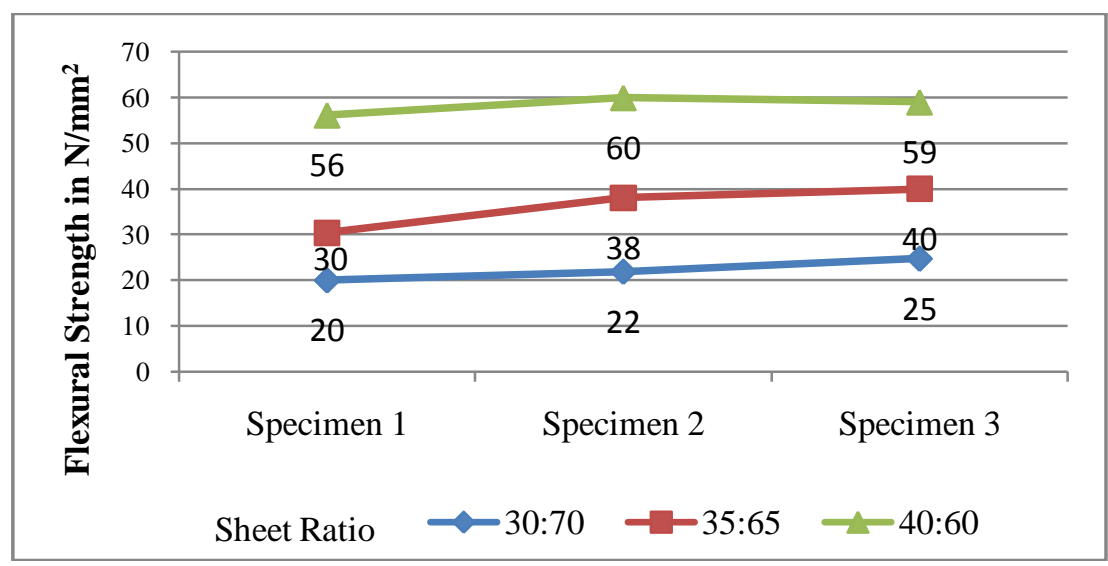

Fig. 06 Flexural strength of glass fiber reinforced polyurethane resin composite vs three different specimen for each ratio

\subsection{IMPACT STRENGTH}

The fig.07 shows the impact strength of three different specimens for each ratio. The results show that there is no major difference in observing the impact strength due to changing the fiber resin ratio. During the impact test the specimen is flexible and it was not broken due to impact load, this shows the elastic property of the material. The composite made of glass fiber reinforced with epoxy will broke due to impact load applied during testing because it has less elasticity comparing with polyurethane resin.Even though the impact strength is more important, from this experimental study the impact strength is not varied much more while the fiber resin ratio is changed.

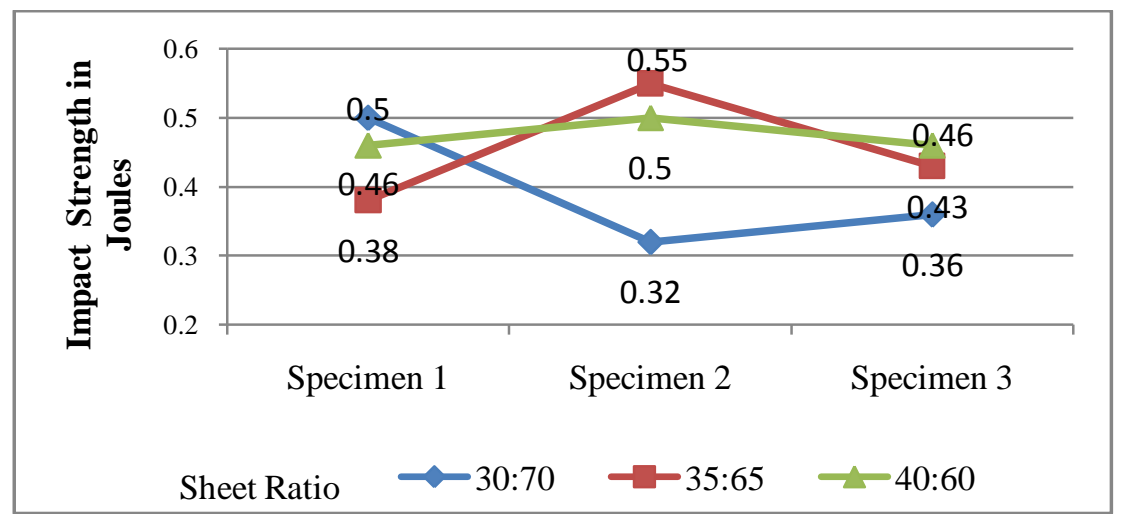

Fig. 07 Impact strength of glass fiber reinforced polyurethane resin composite vs three different specimen for each ratio

\section{CONCLUSION}

The Tensile strength, Flexural Strength and Impact strength of glass fiber reinforced polyurethane resin composite was studied. From the results obtained, the fiber resin ratio 40:60 has more tensile and flexural strength comparing to other two ratios. But there is no big variation in impact strength due to change in ratio. From this experimental study we can conclude that by increasing the fiber content in the composite material the tensile and flexural strength will be increased, but at some point the strength will start decrease due to lack of adhesion material (resin).

\section{REFERENCES}

[1]. P. Hari Sankar, H.Raghavendra Rao, 'Chemical Resistance and Tensile Properties of Bamboo and Glass Fibers Reinforced Epoxy Hybrid Composites'. Advances in Polymer Science and Technology: An International Journal, Vol. 2, Issue.3,2012, page: 27-29

[2]. Nor Hamidah Mohd. Zulfli, Chow Wen Shyang, 'Flexural and Morphological Properties of Epoxy/Glass Fibre/Silane-Treated Organo-montmorillonite Composites'.Journal of Physical Science, Vol. 21, Issue.2,2010, page: $41-50$

[3]. Michael Kupke,Hans-Peter Wentzel,Karl Schulte, 'Electrically conductive glass fibre reinforced epoxy resin'. Mat Res Innovat, Vol. 2, 1998, page: 164-169 
[4]. K.Poyyathappan, K.Pazhanivel, G.B.Bhaskar, S.Arunachalam, M.C.Leninbabu, A.Elayaperumal, 'Fatigue Flexural Properties of Glass FiberReinforced Plastic Composites Subjected to Low Cyclic Impact'. 2nd International Conference on Mechanical, Production and Automobile Engineering,Singapore, April 2012, Page: 28-29

[5]. Girisha.C, Sanjeevamurthy, Gunti Rangasrinivas, 'Tensile Properties of Natural Fiber-Reinforced EpoxyHybrid Composites'. International Journal of Modern Engineering Research (IJMER), Vol.2, Issue.2, Mar-Apr 2012 Page: 471-474

[6]. Srinivasan Arjun Tekalur, Kunigal Shivakumar, Arun Shukla, 'Mechanical behavior and damage evolution in E-glass vinyl ester and carbon composites subjected to static and blast loads'. Composites: Part B, Vol. 39, 2008, Page: 57-65

[7]. M. G. Yilmaz, H. Unal, A. Mimaroglu, 'Study of the strength and erosive behavior of CaCO3/glass fiber reinforced polyester composite'.eXPRESS Polymer Letters, Vol.2, No.12, 2008, Page: 890-895

[8]. N. Rajesh Mathivanan, J. Jerald, 'Experimental Investigation of Woven E-Glass Epoxy Composite Laminates Subjected to Low-Velocity Impact at Different Energy Levels'. Journal of Minerals \& Materials Characterization \& Engineering, Vol. 9, No.7, 2010, Page: 643-652

[9]. A. F. Hamed, M. M. Hamdan, B. B. Sahariand S. M. Sapuan, 'Experimental Characterization of Filament Wound Glass/Epoxy and Carbon/Epoxy Composite Materials'. ARPN Journal of Engineering and Applied Sciences, VOL. 3, NO. 4, August 2008, Page: 76-87

[10]. Mohd. Zulfli, N. H., Abu Bakar A. and Chow W. S, 'Mechanical And Thermal Behaviours Of Glass Fiber Reinforced Epoxy Hybrid Composites Containing Organo-Montmorillonite Clay'. Malaysian Polymer Journal, Vol. 7, No. 1, 2012, Page: 8-15 